\title{
Cellular hypertrophy occurs before interstitial fibrosis in pressure-overload heart failure
}

\author{
Ravi Shah ${ }^{1 *}$, Otavio R Coelho-Filho ${ }^{2}$, Richard N Mitchell ${ }^{1}$, Raymond Y Kwong ${ }^{1}$, Saumya Das ${ }^{3}$, Anthony Rosenzweig ${ }^{3}$, \\ Michael Jerosch-Herold ${ }^{1}$ \\ From 16th Annual SCMR Scientific Sessions \\ San Francisco, CA, USA. 31 January - 3 February 2013
}

\section{Background}

Hypertension is a major risk factor for diastolic heart failure. Hypertension causes cardiac hypertrophy through both individual cardiomyocyte hypertrophy as well expansion of the extracellular matrix. Methods to independently quantify cellular size and fibrosis will improve definition of the pathophysiology of heart failure and opportunities for early intervention.

\section{Methods}

11 mice underwent transverse aortic constriction (TAC). All mice were imaged at baseline, and a group of mice were examined early ( 2 weeks), intermediate (4 weeks) and late (7 weeks) post-TAC with histologic correlation. Mice were imaged at 9.8 Tesla with standard cine function sequences and T1 quantification via a Look-Locker cine experiment, pre and post gadolinium. The intra-cellular lifetime of water ( $\tau$ ic), a-cell size dependent parameter, and the extracellular volume fraction (ECV) were determined by fitting $\mathrm{R} 1$ in tissue, against R1 in the blood pool, with a 2-site model for transcytolemmal water exchange. Minor (Dmin) and major (Dmaj) cell-diameters were determined by image analysis of FITC-wheat germ agglutinin stained sections.

\section{Results}

TAC induced significant and sustained LV hypertrophy $(96.7 \pm 16.7 \mathrm{mg}$ at baseline controls vs. $120.491 \pm 11.702 \mathrm{mg}$ at 2 weeks, $\mathrm{P}<0.05 ; 146.755 \pm 8.167 \mathrm{mg}$ at 4 weeks, $\mathrm{P}<0.05$ vs. baseline controls, $147.767 \pm 8.155$ at 7 weeks, $\mathrm{P}<0.05$ vs. baseline controls). TAC was also associated with a significant decrease in LVEF (all $\mathrm{P}<0.005$ vs. baseline, Table 2). Despite a significant increase in LV mass, mice exposed to TAC did not have as significant an increase in collagen volume fraction or myocardial ECV by CMR at 2 weeks, 4 weeks, or 7 weeks after TAC.

TAC mice showed evidence of increased cardiomyocyte size and volume by cellular dimension at every time point post-TAC ( $\mathrm{P}=0.049$ across time points). TAC mice had progressive increases in $\tau$ ic depending on length of exposure to TAC $(0.218 \pm 0.049$ at 2 weeks, $0.255 \pm 0.031$ at 4 weeks, and $0.488 \pm 0.180$ at 7 weeks, $\mathrm{P}=0.048)$. $\tau$ ic was associated with cellular surface to volume ratio $(\mathrm{r}=0.84, \mathrm{p}=0.001)$.

\section{Conclusions}

Cellular hypertrophy occurs before interstitial fibrosis in mice exposed to pressure-overload. These results suggest that CMR identifies an early, potentially reversible cellular phenotype in diastolic or hypertensive heart failure.

\section{Funding}

Drs. Coelho-Filho and Shah are supported by Post-Doctoral Fellowships from the American Heart Association (AHA 11POST5550053 to OCF and AHA 11POST110033 to RVS). Dr. Kwong is supported in part by a research grant from the National Institutes of Health (NIH RO1 HL 091157). Dr. Jerosch-Herold is supported in part by a research grant from the National Institutes of Health (1R01HL090634-01A1). 


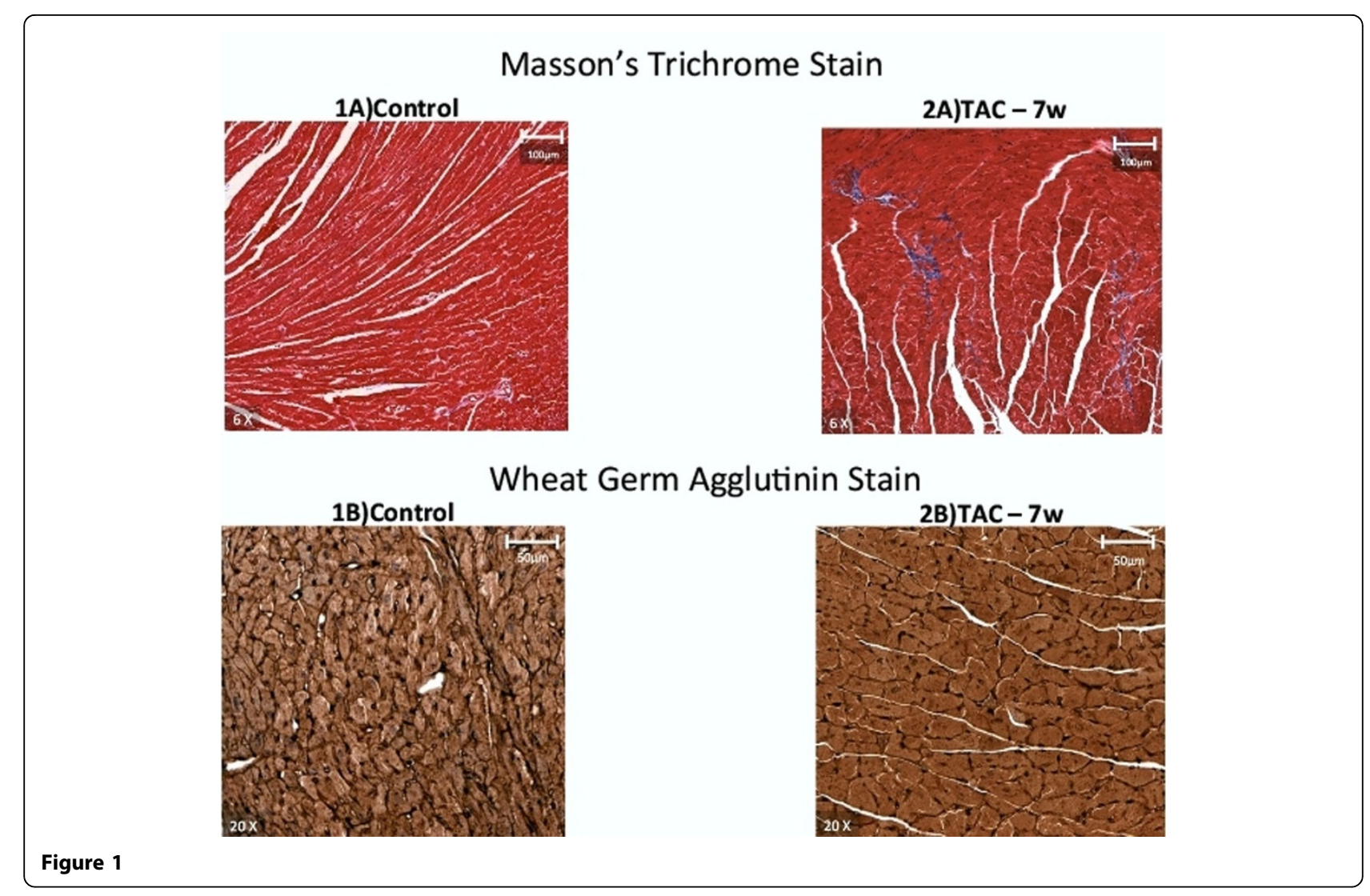

\section{Author details}

'Brigham and Women's Hospital, Boston, MA, USA. 'Department of Internal Medicine, State University of Campinas (UNICAMP), Sao Paulo, Brazil. ${ }^{3}$ Beth Israel Deaconness Medical Center, Boston, MA, USA.

Published: 30 January 2013

doi:10.1186/1532-429X-15-S1-02

Cite this article as: Shah et al:: Cellular hypertrophy occurs before interstitial fibrosis in pressure-overload heart failure. Journal of

Cardiovascular Magnetic Resonance 2013 15(Suppl 1):O2.
Submit your next manuscript to BioMed Central and take full advantage of:

- Convenient online submission

- Thorough peer review

- No space constraints or color figure charges

- Immediate publication on acceptance

- Inclusion in PubMed, CAS, Scopus and Google Scholar

- Research which is freely available for redistribution 